\title{
Using Adjoint-Based Forecast Sensitivity Method to Evaluate TAMDAR Data Impacts on Regional Forecasts
}

\author{
Xiaoyan Zhang, ${ }^{1,2}$ Hongli Wang, ${ }^{3}$ Xiang-Yu Huang, ${ }^{1,4}$ Feng Gao, ${ }^{1}$ and Neil A. Jacobs \\ ${ }^{1}$ National Center for Atmospheric Research, Boulder, CO 80301, USA \\ ${ }^{2}$ Earth System Science Interdisciplinary Center (ESSIC), University of Maryland, College Park, MD 20740, USA \\ ${ }^{3}$ Cooperative Institutes for Research in the Atmosphere (CIRA), Colorado State University, Fort Collins, CO 80523, USA \\ ${ }^{4}$ Centre for Climate Research Singapore, Meteorological Service Singapore, Singapore \\ ${ }^{5}$ Panasonic Avionics Corporation, Morrisville, NC 27560, USA
}

Correspondence should be addressed to Xiaoyan Zhang; xyzucar@gmail.com

Received 7 October 2014; Accepted 22 December 2014

Academic Editor: Guijun Han

Copyright (C) 2015 Xiaoyan Zhang et al. This is an open access article distributed under the Creative Commons Attribution License, which permits unrestricted use, distribution, and reproduction in any medium, provided the original work is properly cited.

This study evaluates the impact of Tropospheric Airborne Meteorological Data Reporting (TAMDAR) observations on regional 24-hour forecast error reduction over the Continental United States (CONUS) domain using adjoint-based forecast sensitivity to observation (FSO) method as the diagnostic tool. The relative impact of TAMDAR observations on reducing the forecast error was assessed by conducting the WRFDA FSO experiments for two two-week-long periods, one in January and one in June 2010. These experiments assimilated operational TAMDAR data and other conventional observations, as well as GPS refractivity (GPSREF). FSO results show that rawinsonde soundings (SOUND) and TAMDAR exhibit the largest observation impact on $24 \mathrm{~h}$ WRF forecast, followed by GeoAMV, aviation routine weather reports (METAR), GPSREF, and synoptic observations (SYNOP). At 0000 and 1200 UTC, TAMDAR has an equivalent impact to SOUND in reducing the 24-hour forecast error. However, at 1800 UTC, TAMDAR has a distinct advantage over SOUND, which has the sparse observation report at these times. In addition, TAMDAR humidity observations at lower levels of the atmosphere $(700$ and $850 \mathrm{hPa})$ have a significant impact on $24 \mathrm{~h}$ forecast error reductions. TAMDAR and SOUND observations present a qualitatively similar observation impact between FSO and Observation System Experiments (OSEs).

\section{Introduction}

Tropospheric Airborne Meteorological Data Reporting (TAMDAR), developed by AirDat (AirDat was acquired by Panasonic Avionics Corporation in 2013), has been providing a continuous operational stream of real-time observations from regional commercial airlines since December 2004. These observations include temperature, winds, water vapor, pressure, icing, and turbulence. Aircraft equipped with TAMDAR typically fly regional routes and cruise at altitudes generally below $25000 \mathrm{ft}$ [1], providing coverage over North America, including Alaska and Mexico, as well as Hawaii, Caribbean, and Europe. TAMDAR was designed to fill in the spatial data voids of traditional Aircraft Meteorological Data Relay (AMDAR) flights, which tend to fly higher altitude routes into major airport hubs with only a small number of planes collecting water vapor, as well as the spatial and temporal data voids of radiosondes, which are launched every $12 \mathrm{~h}$ from limited locations.

The current TAMDAR-equipped fleets make more than 1800 daily flights, providing roughly 3600 radiosonde-like profiles during the ascent and descent phase of flight at various regional and major airports across North America and Europe. The time-based horizontal resolution in cruise is $3 \mathrm{~min}$, and the pressure-based vertical resolution during ascent and descent is $10 \mathrm{hPa}$. The data are transmitted via satellite to a ground-based operation center for quality control and are available for assimilation within $15 \mathrm{~s}$ of sampling [1]. These observations are rapidly becoming a major source of critical data utilized by various assimilation systems for the improvement of mesoscale numerical weather prediction (NWP) and the overall safety of aviation for the future [2]. 
The TAMDAR data have been producing promising impacts on NWP forecasts over the Continental United States (CONUS) for several years and for many different data assimilation systems (e.g., [3-6]), as well as hurricane track prediction [7]. Using the four-dimensional nudging data assimilation method, Liu et al. [4] verified that TAMDAR had a positive impact for mesoscale NWP. Moninger et al. [6] found positive impacts of TAMDAR on $3 \mathrm{~h}$ Rapid Update Cycle (RUC) forecasts of temperature, relative humidity, and winds.

The Weather Research and Forecasting (WRF) community variational data assimilation (WRFDA) system [810] developed at National Center for Atmospheric Research (NCAR) has been enhanced to assimilate TAMDAR observations and investigate TAMDAR data impact on the forecast for hurricane Ike [7]. Their study was followed by further research of observation error tuning [5] to improve the performance of TAMDAR observations in the WRFDA system. Although positive impacts of TAMDAR data on hurricane Ike and regional forecasts were reported, those two previous studies neither compared TAMDAR with other observation types, nor isolated the impact of each observed variable from TAMDAR.

In addition to the traditional observation-denial method, often referred to as Observation System Experiments (OSEs), used in the studies mentioned above, the adjoint-based forecast sensitivity to observation (FSO) method is an efficient approach to assess relative observation impact on a measured aspect of the forecast error. Unlike OSEs, which measure effects of a single observation on all forecast metrics, FSO quantifies the response of a single forecast metric to all perturbations of the observing systems [11]. It can directly assess the impact of any or all observations used by a forecasting system during data assimilation on a selected measure of short-range forecast error, as opposed to adding or withholding observations during assimilation.

The observation impacts from the FSO method can be easily aggregated by various metrics (e.g., observation variable type, data location) providing a powerful tool with potential applications within data assimilation and observing systems. The FSO method has been used in global data assimilation systems to evaluate the observation impact with respect to a scalar function representing the short-range forecast error [11-19]. Two methods of observation impact estimation (i.e., OSEs and FSO) were evaluated and compared by Gelaro and Zhu [19] and by Cardinali [11]. The authors reported qualitatively similar observation impacts on shortrange forecasts using both methods.

In this study, the observation impact of TAMDAR on regional forecasts is evaluated using the adjoint-based FSO method in a limited-area model for two periods in 2010. This evaluation employs the WRF model [20], its adjoint model (WRFPLUS; [21]), and its three-dimensional variational data assimilation (3D-Var) system [10], centered on the CONUS. The adjoint-based FSO tool used in this study was developed by Auligné et al. [22] under the framework of WRFDA. The observation impact from FSO is compared to that from OSEs for TAMDAR and SOUND observations.

The updated WRFDA system with TAMDAR data assimilation capability has been in operation, providing routine analyses and forecasts since 2010. In addition to comparing the overall impact of TAMDAR data with that of other observation types in the operational system, this study also evaluates the impact of TAMDAR on operational short-range forecasts by quantifying the contribution of observed wind $(u, v)$, temperature $(T)$, and moisture $(q)$ using the adjointbased FSO method.

TAMDAR impact can be directly compared to other observations such as SOUND at specific vertical levels or for observed variables. Use of the WRFDA FSO system allows the measurement of TAMDAR observation impact when the entire dataset is present in the data assimilation system. This provides the rank of TAMDAR observational impacts on reducing short-range forecast error with respect to the set of all assimilated observations. It also allows for the identification of problems and refinement of potential features of TAMDAR observations, which are crucial for directing further investigation.

The remainder of this paper is structured as follows. In Section 2, the methods of the forecast sensitivity to observation and the WRFDA FSO system will be described. Section 3 presents the experiment design. Detailed results and comparisons between FSO and OSEs are illustrated in Section 4, and summary and discussions are given in Section 5 .

\section{WRFDA FSO}

The adjoint-based FSO system used in this study is WRFDA FSO, which was developed at NCAR in 2008 [22, 23], and has been verified and employed to examine observation impact in the East Asian region during tropical cyclone seasons [24]. Readers are referred to Jung et al. [24] for a detailed description of the concept of forecast sensitivity to observations and application in the WRFDA system. WRFDA FSO includes the WRF model, its adjoint (WRFPLUS), and WRFDA and its adjoint.

WRFPLUS includes a linearization and its adjoint of the dry dynamics of the WRF model, a simplified vertical diffusion scheme, and a large-scale condensation scheme. There are no other moist processes represented in WRFPLUS. WRFDA FSO is capable of calculating the impact of all available conventional and satellite radiance data on the analysis and short-range forecast. It combines higher order approximations of forecast error measurement and their characteristics in the context of the adjoint-based observation impact calculation discussed by Errico [16], Gelaro et al. [17], Tremolet [25], and Descu and Todling [26].

According to the theory of adjoint-based FSO discussed in previous studies, the calculation of observation impact is a three-step process that involves WRFDA FSO. It seeks the gradient of the forecast error cost function with respect to the vector of observations.

(i) Forecast Sensitivity to Analysis. The calculation of forecast sensitivity to analysis is obtained using two forecast trajectories (i.e., $24 \mathrm{~h}$ ) by the WRF model, which is initialized with the analysis and background, respectively. The background is typically a prior model forecast (e.g., 6-hour forecast), and 


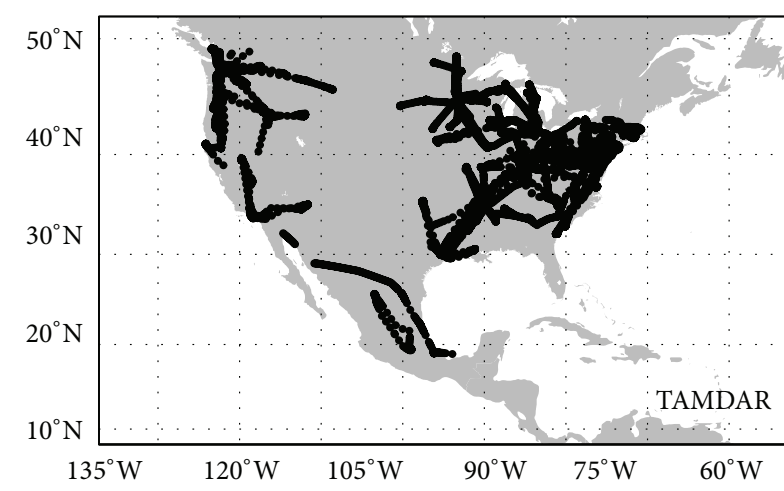

(a)

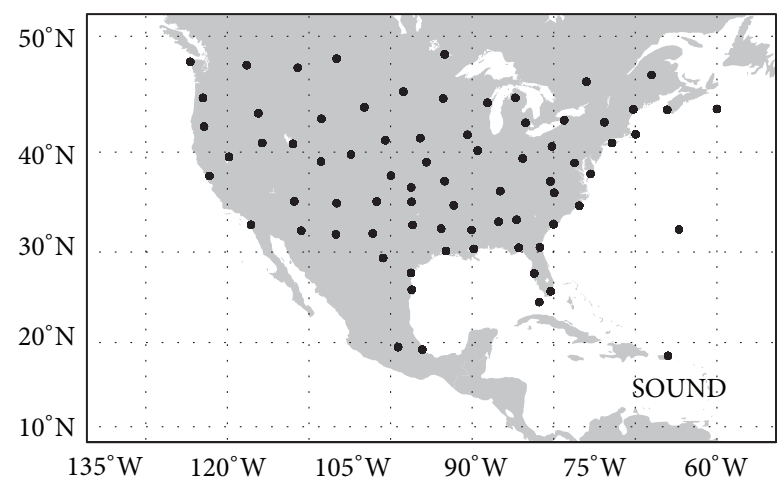

(b)

FIGURE 1: The model geographical configuration with the coverage of TAMDAR (a) and SOUND (b) observations (black dots) at 0000 UTC 2 January 2010.

the analysis is produced by optimally assimilating observations with the background into the WRFDA 3D-Var system. Therefore, the forecast trajectory of the background is starting 6 hours before the trajectory of the analysis. At the forecast time, with a selected reference atmospheric state (REFER) as the truth, the forecast error will be calculated for the forecast of analysis and background. A forecast error cost function will be defined based on the difference between those two forecast errors. Along the forecast back trajectory, the WRFPLUS adjoint model is able to calculate the forecast sensitivity to analysis with the forecast error cost function. In WRFDA FSO, the REFER could be the global analysis from other data assimilation systems or the internal analysis of WRFDA. Detailed methods of forecast sensitivity to analysis are described by ((A.1)-(A.7)) in the Appendix.

(ii) Forecast Sensitivity to Observation. The second step is to extend the forecast sensitivity to analysis from the grid point provided by the previous step into the observation space using the adjoint of WRFDA 3D-Var. It involves the adjoint of the observation operator, observation error covariance, and the inverse of the Hessian matrix of the cost function that can be obtained by using the iterative Lanczos method in the minimization procedure [27]. The formula is provided by ((A.8)-(A.9)) in the Appendix.

(iii) Observation Impact. The observation impact is therefore obtained through calculating the inner product of the forecast error sensitivity to observation and the innovation vector, which is described by (A.9) in the Appendix. This step is implemented within WRFDA and allows users to easily perform various observational impact studies. It should be noted that greater innovation corresponds to greater observation impact. The negative values of observation impact correspond to the forecast error reduction due to improved initial conditions by assimilating observations meaning that the observation has a positive impact on the forecast.

\section{Experiment Design}

The purpose of this study is to compare the impact of TAMDAR data with other observation types in the operational WRFDA system and to evaluate the contribution of TAMDAR wind, temperature, and moisture observations on operational short-range forecasts. Therefore, FSO experiments are conducted over a two-week period for January of 2010 and a two-week period for June of 2010. The WRF model domain for this study has a single $134 \times 84$ grid that covers the US and surrounding oceanic regions (Figure 1) with $60 \mathrm{~km}$ horizontal resolution and 35 vertical levels defined in sigma coordinates with a model top of $50 \mathrm{hPa}$. Compared to the operational CONUS domain run by AirDat, this domain has a much lower resolution and smaller coverage, but it is sufficient to cover the entire North American TAMDAR distribution (Figure 1(a)). This specific configuration is designed for reducing the expensive computational cost of adjoint runs.

WRFDA 3D-Var is used to obtain the analysis by assimilating rawinsonde (SOUND), PILOT, PROFILER, surface data from SYNOP, METAR, SHIP, BUOY, aircraft data from AIREP and TAMDAR, satellite retrieved wind (GeoAMV) and GPS precipitable water (GPSPW), and GPS refractivity (GPSREF). It should be mentioned that the TAMDAR data were provided directly from the AirDat original observing network, instead of TAMDAR data used at National Centers for Environmental Prediction (NCEP), which received approximately $3 \%$ of all available operational TAMDAR observations. The other assimilated datasets come from the Global Telecommunication System (GTS). Figure 1 gives an example of assimilated TAMDAR and SOUND horizontal distribution over the model domain. It should be noted that the restricted Aircraft Communications Addressing and Reporting System (ACARS) data are not used here since they were not available to AirDat in real time.

The quality control (QC) of conventional data including TAMDAR observations in WRFDA is first done in observation preprocessing procedure (obs_proc). Details can be found in the WRFDA user guide (http://www2.mmm.ucar .edu/wrf/users/wrfda/Docs/user_guide_V3.4.1/users_guide chap6.htm). The second QC is taken inside WRFDA before minimization, in which WRFDA does the same QC procedure for TAMDAR data, as well as other conventional data. Observations will be rejected when their innovations are 
larger than 5 times of the standard error of the observation. In this study, no bias correction or thinning procedures are used for TAMDAR data since these functions are not developed in WRFDA, although, compared to SOUND measurement, TAMDAR has the bias of $1.57 \%$ for $\mathrm{RH}$, $-0.04 \mathrm{~K}$ for temperature, and $0.004 \mathrm{~m} / \mathrm{s}$ for wind [5].

The observation error for temperature from TAMDAR used in this study is $1.0 \mathrm{~K}$, which is the same for most observation types in this study, except for SHIP and BUOY with $2.0 \mathrm{~K}$. The wind observation error is $3.6 \mathrm{~m} \mathrm{~s}^{-1}$ for TAMDAR and AIREP, $2.7 \mathrm{~m} \mathrm{~s}^{-1}$ for SOUND, BUOY, SYNOP, and METAR, $2.8 \mathrm{~m} \mathrm{~s}^{-1}$ for PROFILER and PILOT, and $4.5 \mathrm{~m} \mathrm{~s}^{-1}$ for GeoAMV. For TAMDAR relative humidity, we assume the error to be $10 \%$, which is used for other observation types as well in this study. The observation errors are kept uniform for both January and June experiments. The background error covariance (BE) is generated with National Meteorological Center (NMC) method [28] prior to each study period using monthly statistics of differences between WRF 24 and $12 \mathrm{~h}$ daily forecasts over the configuration shown in Figure 1. The same BE is used for both experiments in January and June.

WRFDA 3D-Var is performed each day at 0000, 0600, 1200 , and 1800 UTC with a $6 \mathrm{~h}$ assimilation time window from $-3 \mathrm{~h}$ to $+3 \mathrm{~h}$. The background of every cycle is obtained from the WRF $6 \mathrm{~h}$ forecast initialized from NCEP global final analysis (FNL), instead of the previous WRF analyses. In order to calculate the forecast sensitivity, two $24 \mathrm{~h}$ WRF forecast trajectories are performed for all analysis times, which are initialized with background and analysis, respectively. It is noted here that the $24 \mathrm{~h}$ forecast trajectory of background is starting $6 \mathrm{~h}$ before analysis trajectory. The forecasts utilize the Kain-Fritsch cumulus parameterization [29], Goddard cloud microphysics scheme, and the Yonsei University (YSU) planetary boundary layer parameterization [30]. The $24 \mathrm{~h}$ WRFPLUS adjoint simulations are run along with the WRF trajectory, but only with physical processes of a simple vertical diffusion scheme and a large-scale condensation scheme. All WRFDA 3D-Var and the WRF forecast and WRFPLUS runs use the same model domain configuration and resolution.

For the observation impact calculation, the dry energy norm ((A.3b) in the Appendix) is used to define the forecast error, and the forecast error is calculated for the entire domain (Figure 1). To define the forecast error, the reference analysis that assimilated all observation types described previously with WRFDA 3D-Var is considered the true state in this study. The augmented form of the third-order Taylor series approximation of forecast error discussed by Gelaro et al. [17] is selected for the most accuracy as shown in the Appendix (A.10).

\section{Observation Impact Results}

4.1. Two-Week Time Average. The observation impact of the conventional dataset on the $24 \mathrm{~h}$ forecast error has been investigated at the four synoptic times (i.e., 0000, 0600, 1200 , and 1800 UTC) for two selected periods in January and June, which allows for examining the seasonal variations in the observational impact on the WRF short-range

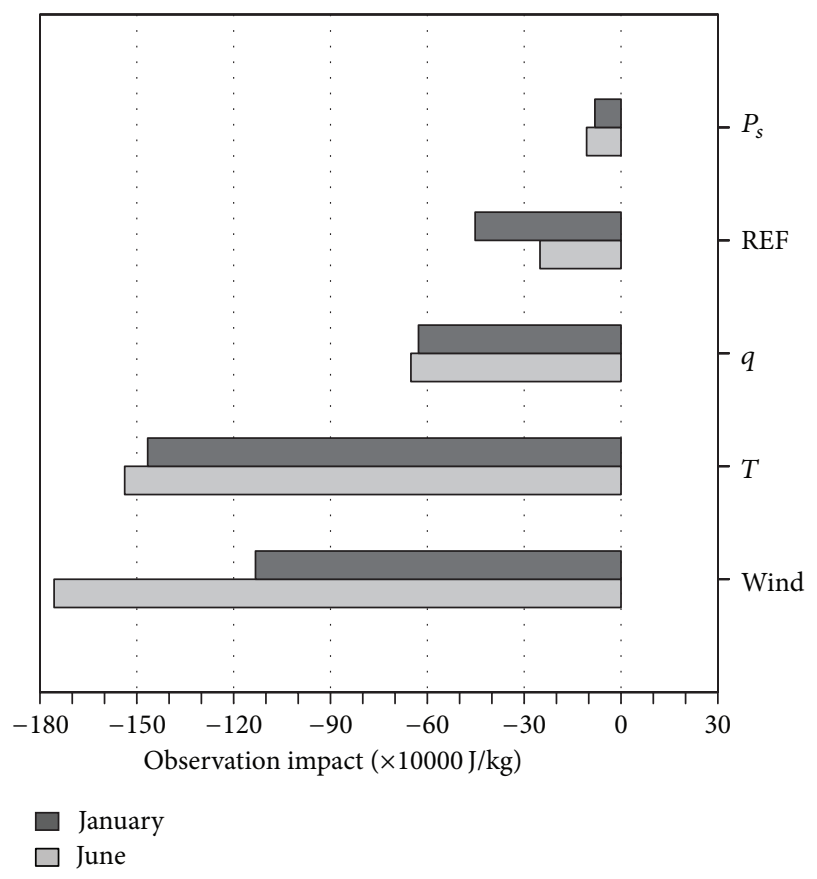

FIgURE 2: Time-average total observation impact $\left(\mathrm{J} \mathrm{kg}^{-1}\right)$ of the types of variables in June (grey) and January (black) 2010. Negative values correspond to a decrease in the energy norm of forecast error. "REF" stands for the GPS refractivity (GPSREF).

forecast during the summer and winter period over the CONUS domain. The two-week time-averaged total observation impacts aggregated with the observation variables (i.e., wind, $T, q, P_{s}$, and REF) over all of the four synoptic times are organized in Figure 2. Negative values correspond to a decrease of forecast error due to assimilating a specific observation variable.

Overall, the forecast error reduction is negative for all variables in two selected periods, implying that the forecast error starting from analysis is smaller than that starting from background. This result also implies that the assimilation of observations in the WRFDA system reduces the forecast error. The observation impact in the two seasons is significantly different for wind observation being larger in June and smaller in January. For January, the largest forecast error decrease is due to temperature observations, followed by wind observations for this specific region and $24 \mathrm{~h}$ forecast length, whereas the largest forecast error reduction for June is due to wind observations followed by temperature observations. The possible reason is that the observation number of GeoAMV from GTS in June 2010 is much more than January for unclear reasons. The next important observation variable to reduce the forecast error is the moisture $(q)$, the refractivity (REF) of GPS, and the surface pressure $\left(P_{s}\right)$. The comparison shows that in general all observation variables except for REF reduce the forecast error by a larger amount in June than in January. The forecast error is highly affected by the synoptic situation, for example, in summer; there are more convective cases than winter. Convective forecasting is usually more challenging in NWP, while the observation amount of GPSREF in the experiment period of January is 


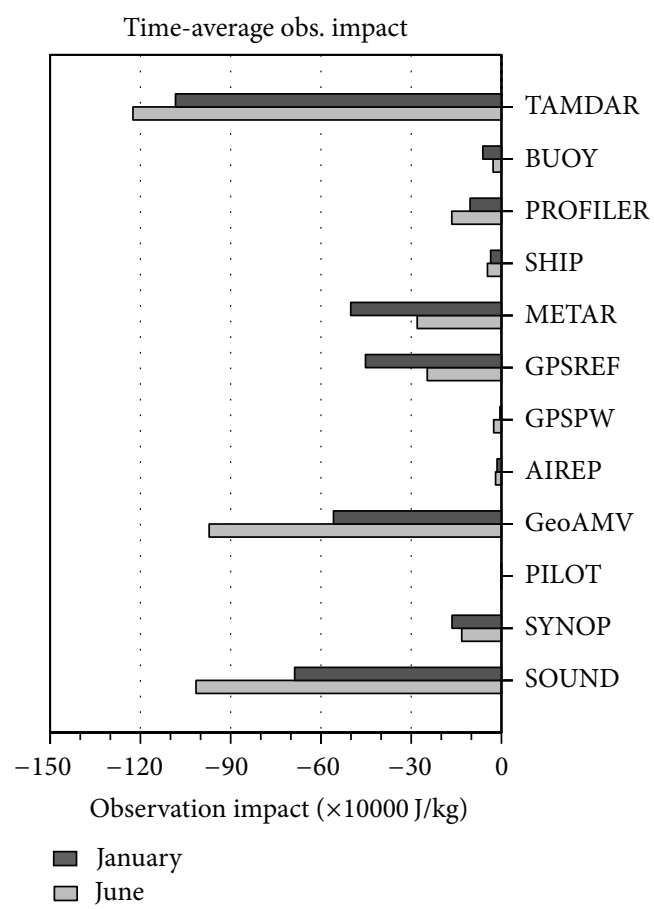

(a)

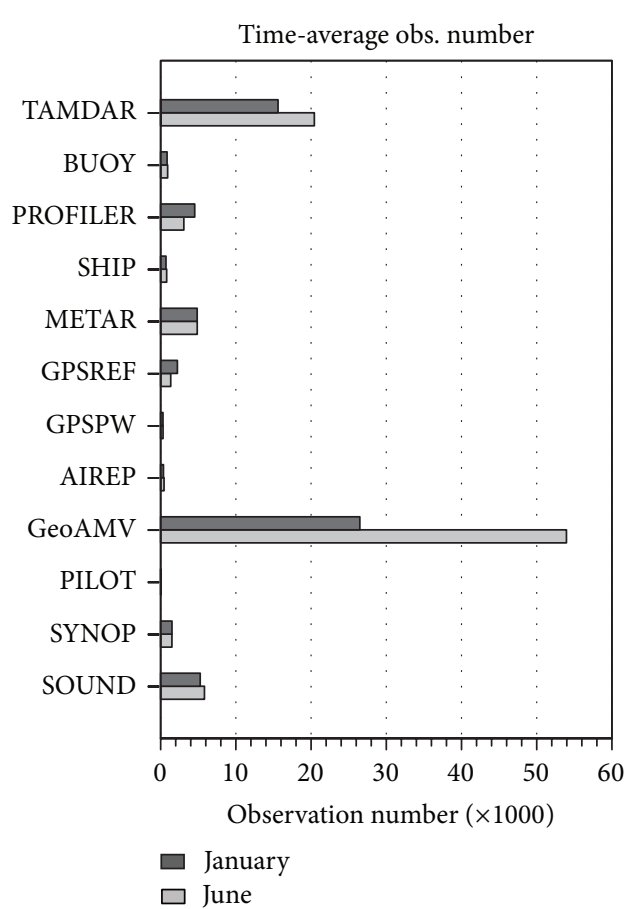

(b)

FIgURE 3: Time-average total observation impact $\left(\mathrm{J} \mathrm{kg}^{-1}\right)$ (a) and the corresponding assimilated observation number (b) of the types of observing systems in June (grey) and January (black) 2010.

more than that in June, which could be the possible reason that GPSREF has larger impact in January than in June.

The time-averaged total observation impact for the various observing systems and the corresponding assimilated observation amount for June and January are grouped in Figure 3. For both June and January, on average all of the observing systems provide the most consistent improvement for $24 \mathrm{~h}$ forecast from season to season, although TAMDAR, SOUND, and GeoAMV drop their impact from summer to winter period. The common seasonal variation exists with smaller observation impact in the winter period and larger in the summer period for each variable (Figure 2) and observing system (Figure 3), which is consistent with the results of Zapotocny et al. [31]. Therefore, Figure 3 suggests that the WRFDA properly assimilated these observations and improved the initial conditions of the forecast. Overall, for two selected periods, the largest forecast error reduction is due to TAMDAR and SOUND, followed by GeoAMV, METAR, GPSREF, PROFILER, SYNOP, and PILOT. The total forecast error reductions from AIREP, GPSPW, BUOY, and SHIP are smaller because of their sparse coverage with limit data amount as shown in Figure 3(b). The primary reason for the small impact from AIREP is that the ACARS is a restricted dataset and not available for operational assimilation by nongovernmental agencies. Figure 3(b) shows that the assimilated AIREP observation numbers are obviously less than others. We expect that this would be a dominant observing system if ACARS data were included in this study (e.g., [32]).
From the cross-reference of Figures 3(a) and 3(b), the assimilated observation numbers of TAMDAR are much more than SOUND. This is the main reason that TAMDAR data are leading the observation impact in this system when considering that they have the same observed variables (wind, temperature, and humidity) and similar observation errors as SOUND. GeoAMV also has a large observation number; however, the impact is not as obvious as TAMDAR and SOUND because it is only located at certain levels and with only wind observations and larger observation error (Section 3). The observation number of GeoAMV from GTS in June 2010 is much more than January for unclear reasons, which certifies that the larger observation impact of GeoAMV in summer versus winter period is closely related to the number of datasets.

The surface observation types SYNOP, METAR, BUOY, and SHIP have similar trends in the summer and winter period. However, the observation impact is slightly different with an increase from summer to winter period, even with equivalent observation numbers and the same observation error. This difference appears to be a result of the WRF 24hour forecast error for the surface, which is larger in January than in June. With the surface pressure instrument, METAR, observation impact is significantly different in winter versus summer period; however, this does not change the total $P_{s}$ observation impact between the winter period and summer period in Figure 2. The reason is the $P_{s}$ in Figure 2 including the surface pressure observation from SOUND and SYNOP in the WRFDA FSO procedure. 


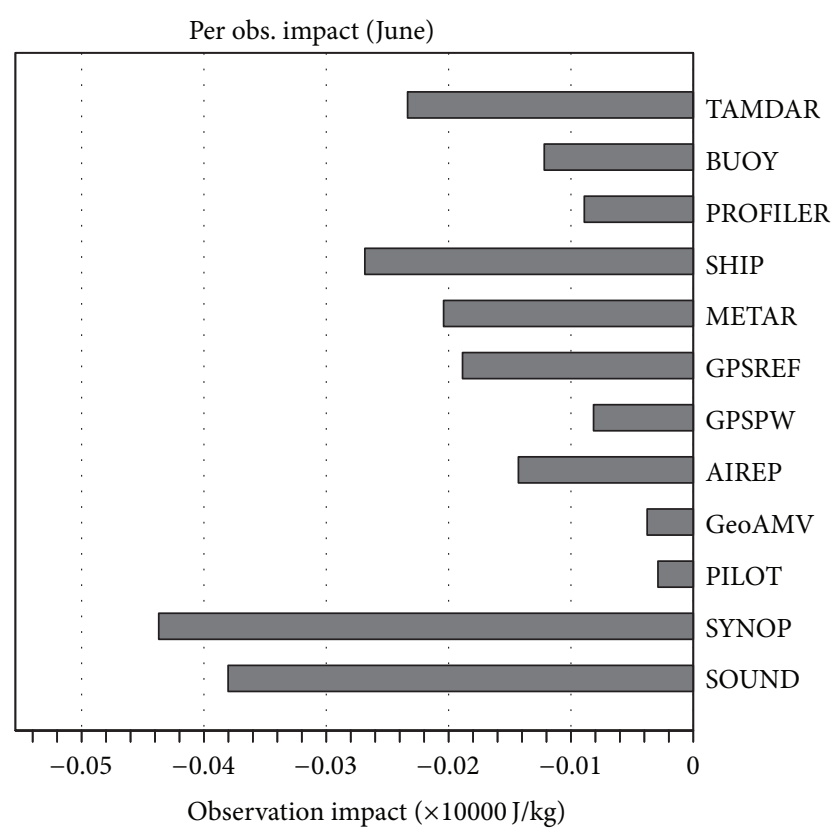

FIGURE 4: Time-average per-observation impact $\left(\mathrm{J} \mathrm{kg}^{-1}\right)$ for June 2010, which is time-averaged total observation impact divided by the observation number.

In order to evaluate the normalized observation impact, the observation impact per observation numbers for all assimilated observation systems in June is calculated (Figure 4), which is the averaged observation impact (shown in Figure 3(a)) divided by the observation number (shown in Figure 3(b)). January has a similar per-observation impact, and the redundant figure is not shown here. Figure 4 indicates that SYNOP surface observations have the greatest normalized observation impact, although they have a relatively small contribution to the total observation impact as shown in Figure 3(a). It means every single SYNOP observation contains important information to reduce model surface forecast error which is usually larger and more difficult than the upper air for model forecast. The rank of other normalized observation impacts is in order of SOUND, TAMDAR, GeoAMV, METAR, and GPSREF from high to low. The TAMDAR observation, which has the greatest total impact, has a smaller normalized observation impact than SOUND. The reason is likely because TAMDAR uses a larger wind observation error $\left(3.6 \mathrm{~m} \mathrm{~s}^{-1}\right)$ than that of SOUND $\left(2.7 \mathrm{~m} \mathrm{~s}^{-1}\right)$. Additional comparisons between these two observing systems will be addressed in the following sections with greater detail.

4.2. Observation Impact across Four Synoptic Times. In the previous section, it was shown that the assimilation of large sets of observational data reduces the $24 \mathrm{~h}$ WRF regional forecast error. However, the observation impact of individual observations varies widely, and the adjoint-based calculation allows us to quantify this impact for every observation at a particular analysis time. The time-averaged observation impact and dataset count for all assimilated observations across four synoptic times are shown in Figure 5 for summer period only. Since the seasonal impact difference is understood from previous discussion of Figures 2 and 3, the redundant winter figure is omitted.

It is noted that the observation impact corresponds to the observation number when comparing Figures 5(a) and 5(b), and the observation impact of TAMDAR, SOUND, and GEOAMV varies with four synoptic times. For TAMDAR, its observation impact at 0000 UTC is the largest, 0600 UTC is the smallest, and 1200 and 1800 UTC are the closest. The observation impact of TAMDAR at 1200 UTC is slightly less than 1800 UTC, although the data amount at 1200 UTC is much less than 1800 UTC. The observation number at 1800 UTC is the greatest, followed by 0000,1200 , and 0600 UTC, which is expected based on the commercial airline flight times. The observation impact in Figure 5(a) indicates a smaller TAMDAR observation impact at 1800 UTC compared to 0000 UTC, even though the observation number (Figure 5(b)) at 1800 UTC is more than 0000 UTC. This mismatch may be because observations are more numerous but do not necessarily result in an automatically a larger impact if observation error correlations and the thinning are not properly used.

The largest observation impact of SOUND is at 1200 UTC, followed by 0000,1800 , and 0600 UTC, which is consistent with its observation number in Figure 5(b). GeoAMV observation impact was the third largest one in the system; however, it has less obvious time variation than that of TAMDAR and SOUND. GeoAMV has the same issue as TAMDAR at 1800 UTC; largest observation numbers do not bring the largest observation impact. This performance suggests that WRFDA may need more attention and effort to handle data density for assimilation. The other possible reason for the performance of GeoAMV could be that larger observation error was introduced to GeoAMV wind observation as described in Section 3. METAR and GPSREF have a comparable impact following GeoAMV at all analysis times. With smaller observation numbers, METAR, GPSREF, and PROFILER have relative large observation impacts. Based on (A.10) in the Appendix, the observation impact is depending on two elements: the departure of observation and background $(d)$ and model forecast error. It means that the model forecast error is larger on the locations of METAR, GPSREF, and PROFILER, and these data contain important information to reduce the forecast error to a great extent. The surface observation instrument, SYNOP, produces an equally important impact for $0000,0600,1200$, and 1800 UTC in this study, due to the equal data report amount along with those times.

The comparison between TAMDAR and SOUND shows that at 0000 UTC the observation impact from SOUND is similar to TAMDAR, and at 1200 UTC, SOUND produces more impact than TAMDAR. At 0600 and 1800 UTC, however, since SOUND has only a few records, TAMDAR has a much greater observation impact than SOUND. The amount of TAMDAR observations is significantly larger than SOUND at all assimilation times. Particularly at 1800 UTC when SOUND reports are sparse, TAMDAR observation has the thickest coverage due to the high peak of commercial flights landing and takeoff at local airport. The averaged total 


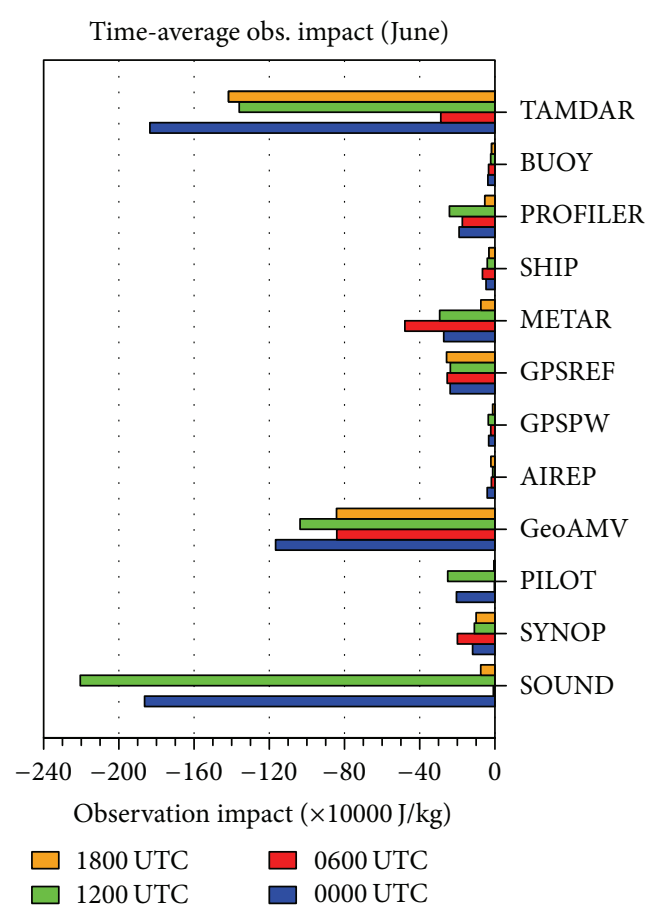

(a)

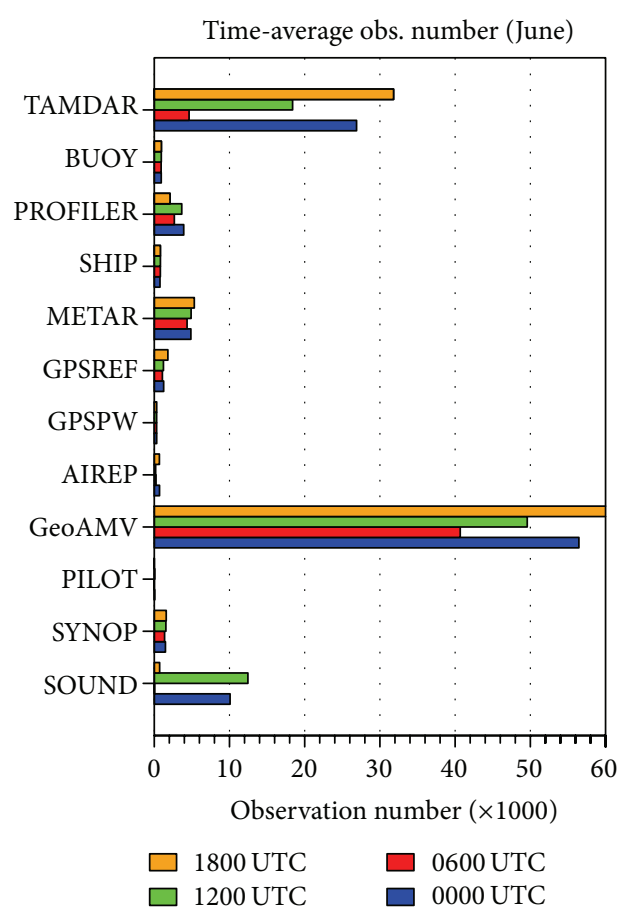

(b)

FIGURE 5: Time-average total observation impact on $24 \mathrm{~h}$ forecast $\left(\mathrm{J} \mathrm{kg}^{-1}\right)$ (a) and the corresponding assimilate observation number (b) of the types of observing systems for 0000 (blue), 0600 (red), 1200 (green), and 1800 (orange) UTC in June 2010.

observation impact illustrates that TAMDAR has a distinct advantage at $1800 \mathrm{UTC}$ in reducing the $24 \mathrm{~h}$ forecast error due to the dense observation record. Therefore, the larger total observation impact of TAMDAR than that of SOUND (Figure 3) mostly likely originates from the contribution of 1800 UTC observations.

4.3. Observation Impact Vertical Distribution. Since TAMDAR and SOUND have similar observation impacts discussed in Sections 4.1 and 4.2, and TAMDAR is a rawinsondelike observation with the same observational variables, the comparison is made between TAMDAR and SOUND to investigate why the observation impact of TAMDAR is greater than SOUND at some analysis times. Figure 6 presents the vertical distribution of the time-averaged wind observation impact and observation number for TAMDAR and SOUND for the summer period at 0000 UTC. The observation impact is categorized for eight vertical levels: $1000,850,700,500,300,200,100$, and the model top (50) hPa. From the vertical distribution, both TAMDAR and SOUND present the positive impact at all vertical pressure levels for wind. It can be seen from Figure 6(a) that TAMDAR wind observation impact resides primarily below $300 \mathrm{hPa}$ corresponding to its cruise altitude below $25000 \mathrm{ft}$. At $500 \mathrm{hPa}$, TAMDAR shows a larger observation impact than SOUND corresponding with larger observation number in Figure 6(b). However, at 1000, 850, 700, and $300 \mathrm{hPa}$, TAMDAR presents smaller observation impact than SOUND although TAMDAR has more observation at these levels. It is likely a function of the model-assigned larger observation error for TAMDAR wind observations than that of SOUND. Gao et al. [5] presented revised lower TAMDAR-specific error values, which, prior to TAMDAR, were set to the same values as AIREP.

The observation impact vertical distribution for temperature $(T)$ and water vapor mixing ratio $(q)$ are displayed for June in Figure 7, as well as the corresponding observation number. The $q$ in Figure 7(c) is converted from the observed relative humidity $(\mathrm{RH})$ in WRFDA. Since the adjoint model does not account for the majority of moist processes, the error of humidity impact is assumed to be ignored for the preliminary investigation in this study. Therefore, it must be declared that the humidity impact mentioned here only counts the contribution to dry energy norm. However, it is fair to make approximate comparisons of the humidity impact between TAMDAR and SOUND in the same system.

As with wind, both $T$ and $q$ show the positive impact to forecast at all vertical levels. In Figures 7 (a) and 7(c), at 850 and $700 \mathrm{hPa}$, TAMDAR shows a larger $T$ and $q$ observation impact than other levels corresponding to the more observations in Figures 7(b) and 7(d); however, SOUND presents smaller observation impact at these two levels corresponding with fewer observations than TAMDAR. Therefore, the dense TAMDAR observations compensate sparse SOUND reports in the critical vertical region (lower levels) where no other moisture data is available. This analysis suggests that the humidity observation of TAMDAR has a positive impact on the WRF regional $24 \mathrm{~h}$ forecast, especially at lower levels (700 and $850 \mathrm{hPa}$ ) where convective weather originates. 


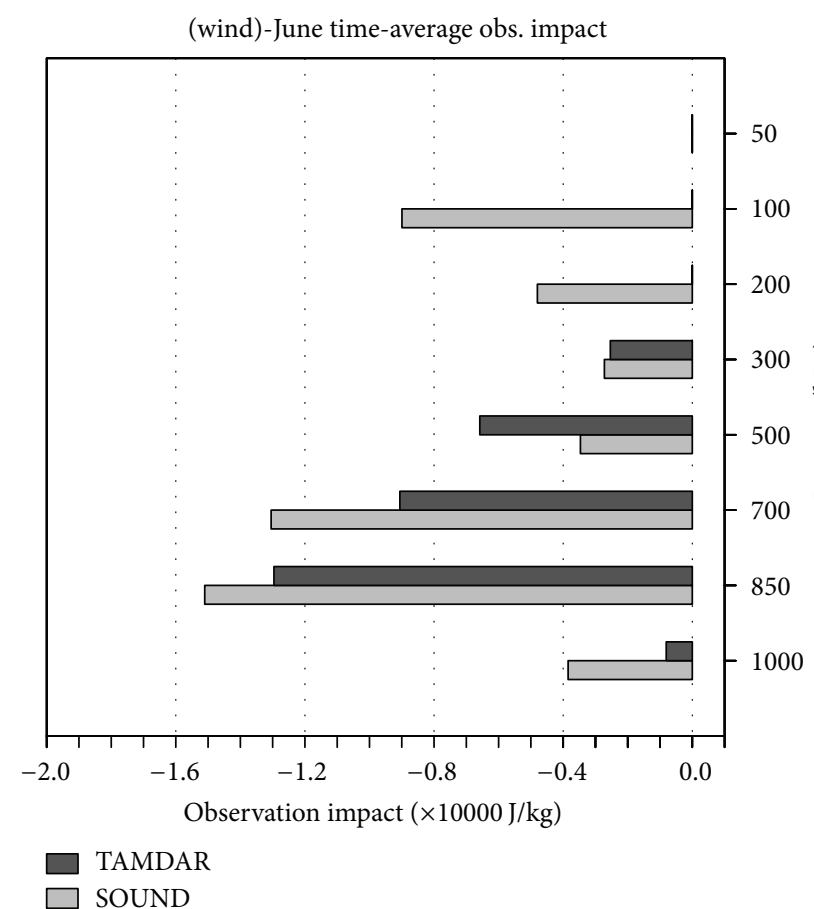

(a)

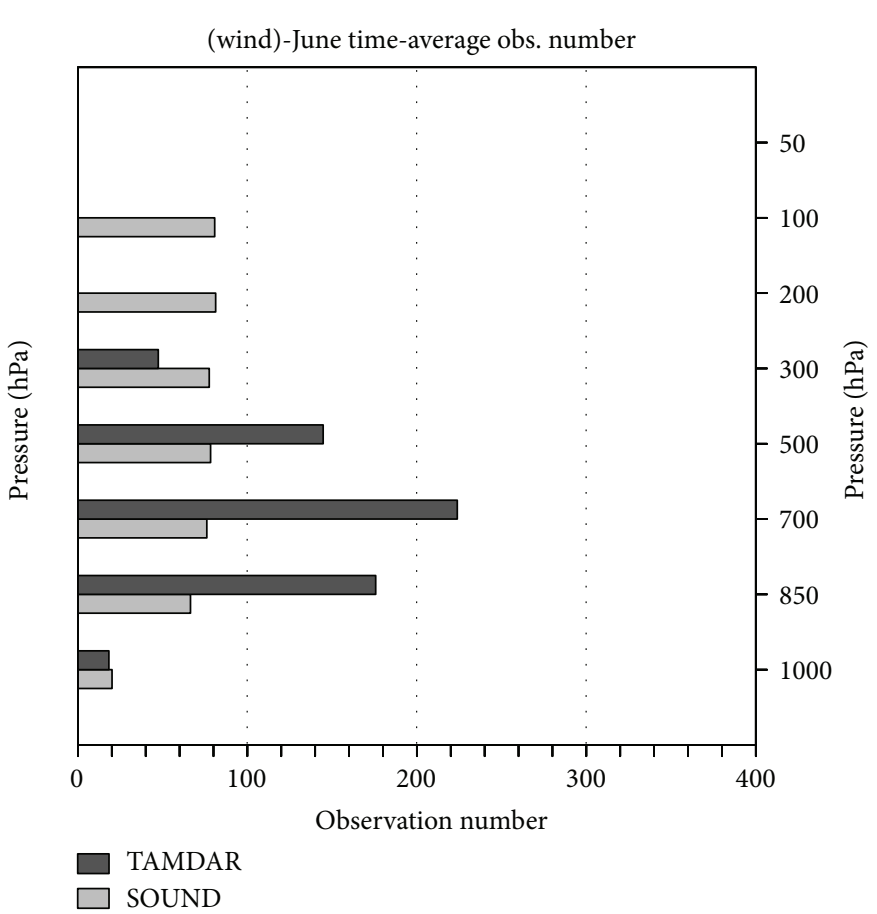

(b)

FIgURE 6: Time-average observation impact $\left(\mathrm{J} \mathrm{kg}^{-1}\right)$ of TAMDAR and SOUND wind (a) on pressure levels (hPa) from $1000 \mathrm{hPa}$ above the surface up to $50 \mathrm{hPa}$ at $0000 \mathrm{UTC}$ in June 2010; (b) is the observation number at corresponding vertical levels.

4.4. OSEs. In previous sections, the linear estimations of observation impact are described. This section compares the impact of observations on $24 \mathrm{~h}$ forecast evaluated using typical OSEs with that evaluated using the adjoint-based FSO method. The REFER that assimilates all observation types (Section 3) is used as a control experiment that is referred to as OSE-ALL. Two OSEs are then conducted by performing new analysis-forecast cycles for a given period (i.e., from 1 to 15 June 2010). In the new analysis procedure, the TAMDAR and SOUND to be evaluated are removed from the observation set in data denial experiments. The corresponding OSEs are referred to as OSE-TAMDAR and OSESOUND, respectively. Through a series of OSEs, the impact of TAMDAR and SOUND is evaluated. The configurations of the analysis and forecast system are the same as those described in Section 3 for FSO.

The observation impact of TAMDAR from OSEs is defined as the difference of $24 \mathrm{~h}$ forecast error of OSE-ALL and OSE-TAMDAR. The calculation of forecast error for OSE-ALL and OSE-TAMDAR uses the formulation in the Appendix (A.6) with the same REFER as the true state as the FSO described in Section 3. OSE-SOUND followed the same procedure as OSE-TAMDAR to get the observation impact of SOUND. Figure $8(\mathrm{a})$ presents the time-averaged observation impact for both OSE-TAMDAR and OSE-SOUND in June at 0000, 0600, 1200, and 1800 UTC.

The TAMDAR and SOUND observation impact obtained from FSO are compared in Figure 8(b). The largest observation impact of TAMDAR is at 1800 UTC, which is even larger than the error of removing SOUND observation and is consistent with the results of FSO (Figure 8(b)). Likewise, the observation impact of SOUND data is larger at 1200 UTC than TAMDAR data. At 0000 UTC, the OSEs show that TAMDAR results in slightly larger observation impact than SOUND, whereas FSO presents equal impact between TAMDAR and SOUND. 0600 UTC is only showing the impact of TAMDAR for both OSEs and FSO. The comparable pattern demonstrates that FSO and OSEs show similar importance at each synoptic time. The WRFDA FSO diagnostic tool is capable of highlighting the major forecast degradation due to the observations withheld compared with OSEs. However, using cross comparisons of the magnitude of observation impact between OSEs and FSO, the difference shows larger observation impact of OSEs than that of FSO. This means the linear estimate forecast error reduction from FSO method slightly underestimates that from the nonlinear method in the OSEs. This underestimation may be due to the (1) neglected moist physics in adjoint integration, (2) the validity of the tangent linear assumption, and/or (3) the validity of the tangent linear assumption of the forecast error reduction. OSEs measure the effects of either SOUND or TAMDAR on all forecast metrics; FSO quantified the response of a single metric to all observations including TAMDAR and SOUND. Overall, the comparable results still demonstrate that the FSO and OSEs show similar qualitative improvements due to TAMDAR and SOUND observations. 


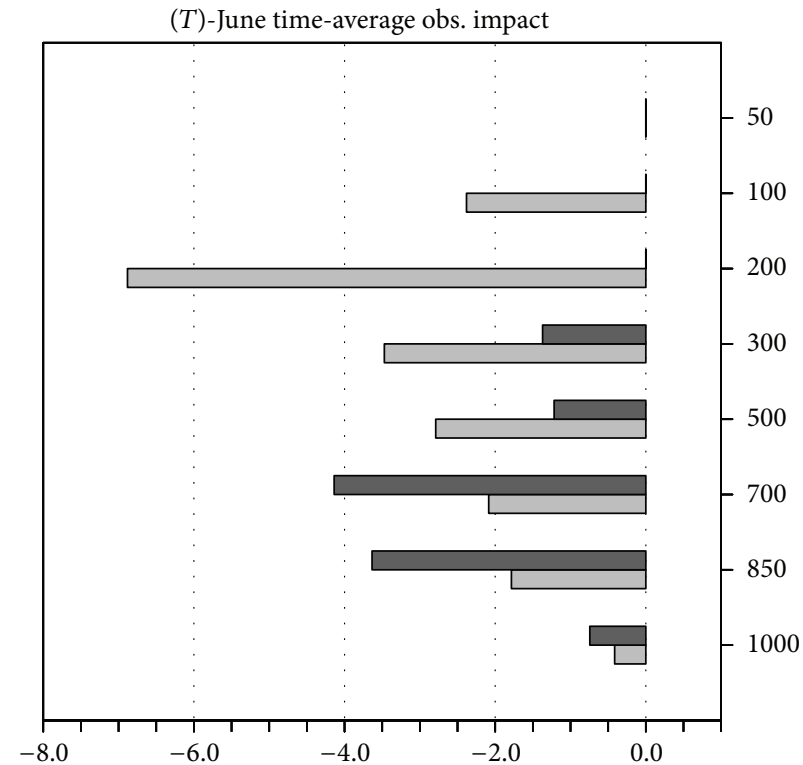

(a)

(q)-June time-average obs. impact

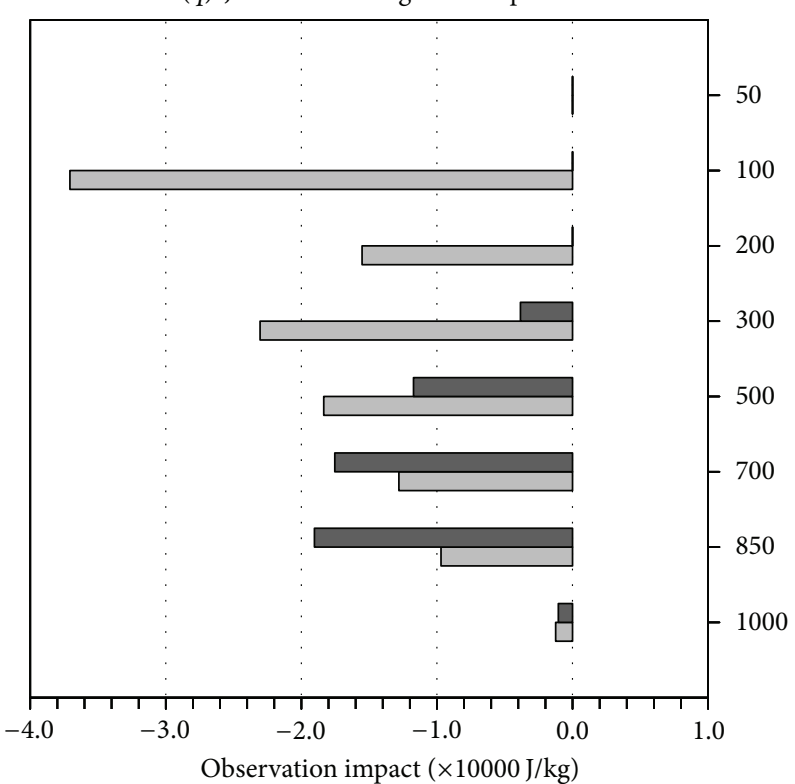

TAMDAR

SOUND

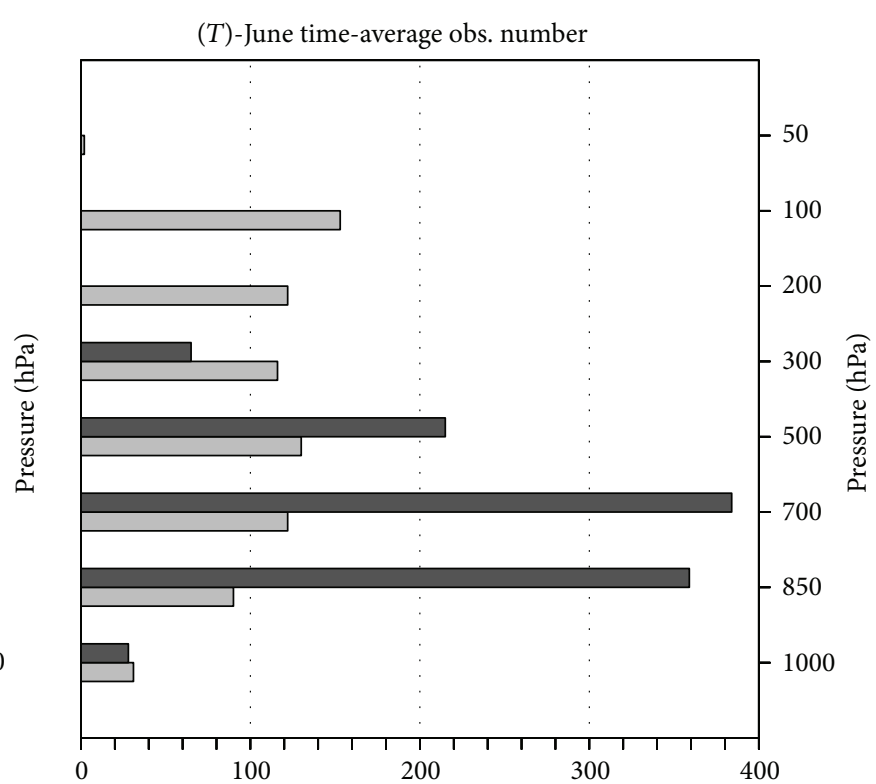

(b)

(q)-June time-average obs. number

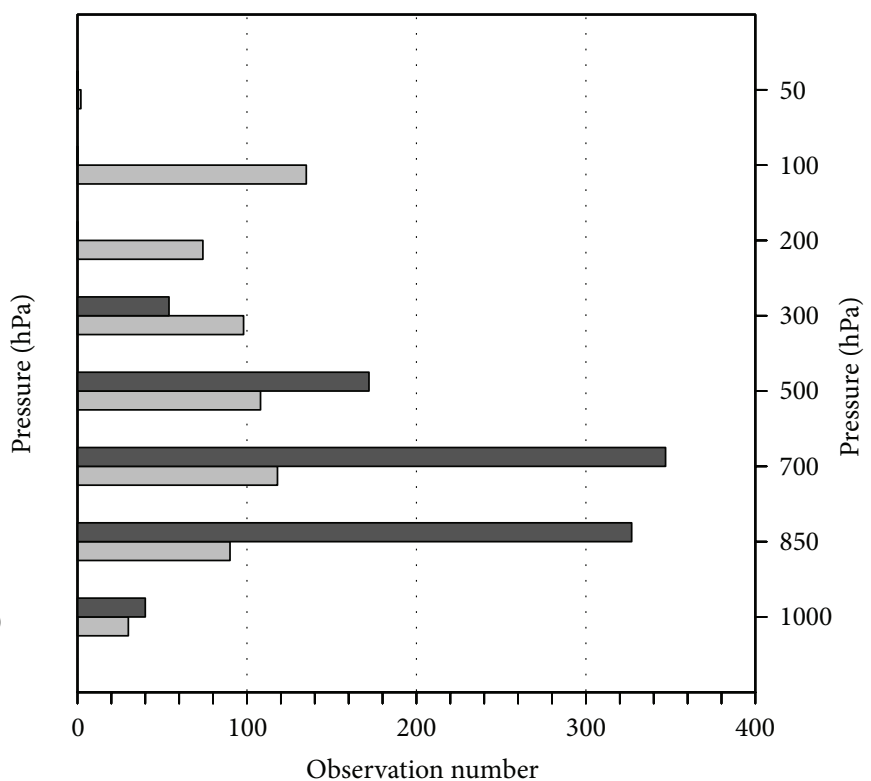

TAMDAR

SOUND

(c)

(d)

FIgURE 7: Time-average observation impact $\left(\mathrm{J} \mathrm{kg}^{-1}\right)$ of (a) temperature $(T)$ and (c) specific humidity $(q)$ from TAMDAR and SOUND on pressure level (hPa) from $1000 \mathrm{hPa}$ above the surface up to $50 \mathrm{hPa}$ at $0000 \mathrm{UTC}$ in June 2010; (b) and (d) are the observation number of $T$ and $q$, respectively, at the corresponding vertical level.

\section{Summary and Discussions}

This paper presents an application of the WRFDA FSO system for estimating the impact of observations on regional forecasts and investigates influence of TAMDAR data on short-range $(24 \mathrm{~h})$ forecast error reduction. A significant advantage of the FSO method is that observation impact can be efficiently estimated for a complete set of observations, or any subset of observations grouped by type of observing system, observed variable, geographic region, vertical level, or other categories. The assessment of the value of TAMDAR and SOUND observations impact through the OSEs is also performed, which demonstrates that the FSO experiments and OSEs provide similar qualitative diagnostic results. The 


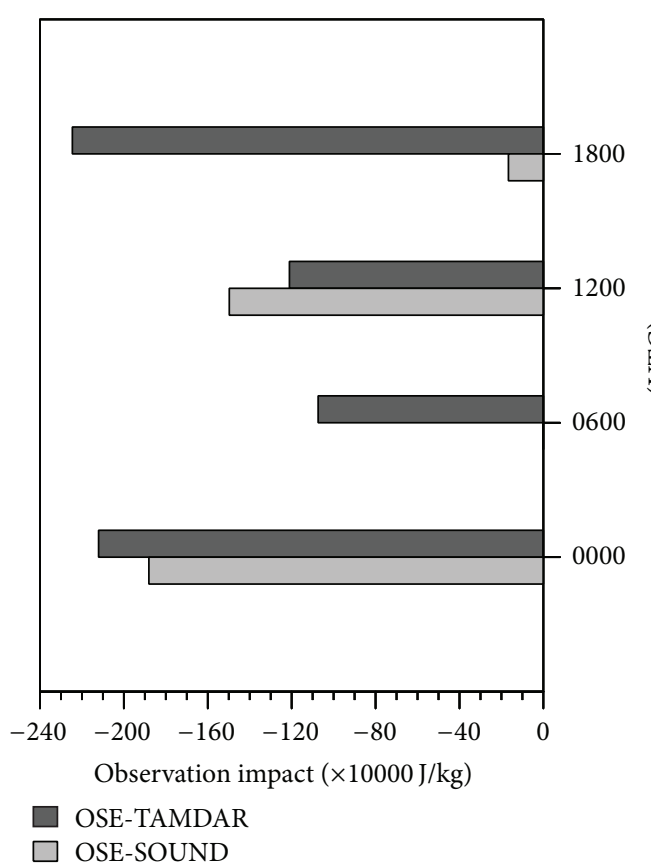

(a)

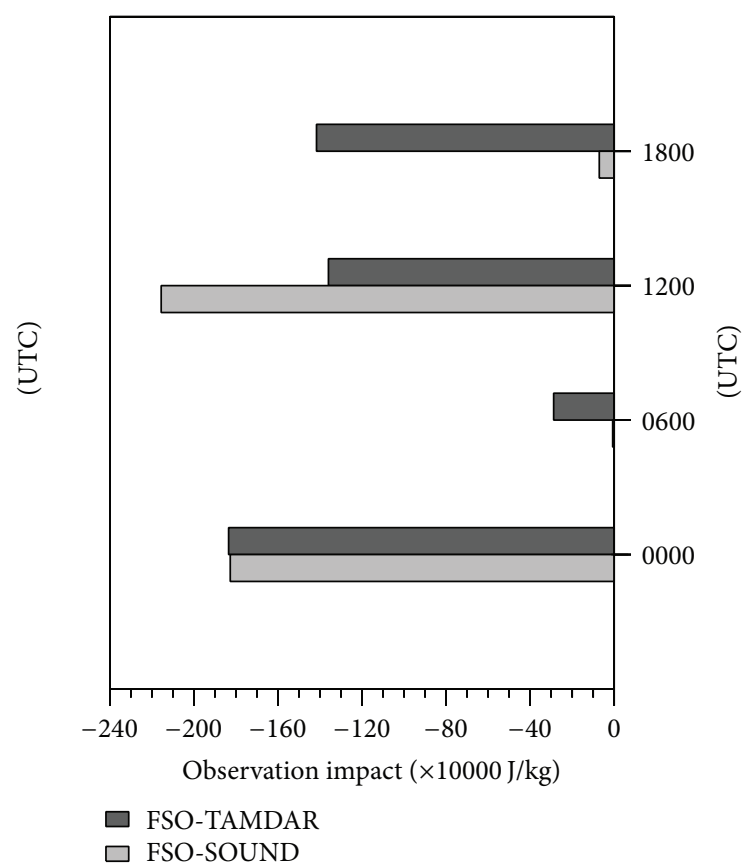

(b)

FIGURE 8: Two-week averaged observation impact $\left(\mathrm{J} \mathrm{kg}^{-1}\right)$ of OSEs (a) for removing TAMDAR (OSE-TAMDAR) and SOUND (OSESOUND), respectively, and the observation impact of TAMDAR (FSO-TAMDAR) and SOUND (FSO-SOUND) from FSO (b) in June 2010.

FSO method also requires fewer computational resources than OSEs and can monitor the observation impact in an operational framework.

FSO results suggest that on average all the observing systems play a positive role in reducing the $24 \mathrm{~h}$ forecast error. The wind and temperature in the observation system make key contributions to reduce the $24 \mathrm{~h}$ forecast error, although the largest observation impact for June is wind, whereas it is, for January, temperature. The largest observation impact is produced by SOUND and TAMDAR and followed by GeoAMV, METAR, GPSREF, and SYNOP. However, most instruments have the seasonal variation with the larger impact in summer period than winter period. The wind, temperature, and relative humidity observations of TAMDAR have significant contributions in the operational WRFDA system, particularly at 1800 UTC.

FSO observation impact was compared to the observation impact deduced from OSEs that were performed as data denial experiments for TAMDAR and SOUND. Consistent with FSO impact results, the total observation impact of TAMDAR from OSEs is larger than SOUND at 0600 and 1800 UTC, and impact at 0000 UTC is similar to SOUND, and impact at 1200 UTC is less than SOUND. Whilst OSEs are more indicated for evaluating the longer term forecast impact of data, FSO is still a good choice to investigate the short-range forecast error reduction due to the observations. FSO is able to evaluate the impact of observations when the entire observation dataset is present in the assimilation system with one experiment, while OSEs have to perform more than one experiment to evaluate the contribution from different datasets [11].
The advantages of TAMDAR data in the operational WRFDA system are reinforced through this study using the FSO approach and include the following.

(i) The total observation impact of TAMDAR is obvious at 0000,1200 , and 1800 UTC cycle consistently. TAMDAR at 1800 and 0600 UTC is able to complement SOUND observations to reduce forecast error.

(ii) TAMDAR relative humidity and temperature observation are a very important supplement to SOUND data at lower levels, especially at 850 and $700 \mathrm{hPa}$.

Additionally, a few issues have been noticed with the adjoint-based observation impact estimate. First, the calculation of the sensitivity used in the WRF adjoint is limited by simple physical schemes. Secondly, the definition of the forecast error norm does not include moisture. A greater impact from moisture observation might be expected when more moist physics schemes are included in the WRF adjoint model and a total moist energy norm is used.

In this study, no bias correction or thinning procedures are used for TAMDAR data since these functions are not developed in WRFDA. As discussed in Section 2, the observation innovation and observation number directly affect the forecast error reduction. The bias correction is clearly related to the innovation, and the thinning procedure decides how many data will be assimilated. Therefore, additional work is needed to address the bias correction and thinning procedure to improve the accuracy of observation impact of TAMDAR in FSO system. Inclusion of moisture in total energy and investigation of the influence of TAMDAR data 
thinning and bias correction strategy on short-term forecast error reduction should be part of future development. The new observation error for TAMDAR has been estimated and added in WRFDA [5]. It would be also interesting to study the forecast sensitivity to TAMDAR observation errors with FSO.

\section{Appendix}

\section{Basic Concept of Observation Impact}

The nonlinear forecast model can be expressed as

$$
\mathbf{x}^{f}=M\left(\mathbf{x}^{0}\right)
$$

where $M$ is the nonlinear propagator of the model for the time period $0 \leq t \leq f$ and $\mathbf{x}^{f}$ is the forecast model state vector at time $t=f$ with initial condition vector $\mathbf{x}^{0}$. Given a perturbation $\delta \mathbf{x}^{0}$ at the initial time, the linear evolution $\delta \mathbf{x}^{f}$ at time $t=f$ is

$$
\delta \mathbf{x}^{f}=\mathbf{M} \delta \mathbf{x}^{0}
$$

where $\mathbf{M}$ is the tangent-linear propagator of $M$ along the forecast trajectory initiated from $\mathbf{x}^{0}$. To study the observation impact on forecasts, the forecast error, which is measured with respect to the true atmospheric state $\mathbf{x}_{t}^{f}$ at time $t=f$, is defined as

$$
e=\left\langle\mathbf{x}^{f}-\mathbf{x}_{t}^{f}, \mathbf{C}\left(\mathbf{x}^{f}-\mathbf{x}_{t}^{f}\right)\right\rangle
$$

where $\langle\cdot, \cdot\rangle$ denotes the Euclidean inner product of two vectors and $\mathbf{C}$ is a diagonal matrix that has the weighting coefficients of the forecast error components. Usually, the dry total energy norm is used for $\mathbf{C}$ [33-35] as

$$
e=\sum_{i, j, k}\left[u^{\prime 2}+v^{\prime 2}+\left(\frac{g}{\bar{N} \bar{\theta}}\right)^{2} \theta^{\prime 2}+\left(\frac{1}{\bar{\rho} c_{s}}\right)^{2} p^{\prime 2}\right] .
$$

Using (A.2), the sensitivity (gradient) of $e$ to initial conditions is expressed as

$$
\frac{\partial e}{\partial \mathbf{x}^{0}}=2 \mathbf{M}^{T} \mathbf{C}\left(\mathbf{x}^{f}-\mathbf{x}_{t}^{f}\right)
$$

Given two forecasts $\mathbf{x}_{b}^{f}$ and $\mathbf{x}_{a}^{f}$ with the background $\left(\mathbf{x}_{b}^{0}\right)$ initial condition and analysis $\left(\mathbf{x}_{a}^{0}\right)$, respectively, the forecast error is

$$
\begin{aligned}
& e_{b}=\left\langle\mathbf{x}_{b}^{f}-\mathbf{x}_{t}^{f}, \mathbf{C}\left(\mathbf{x}_{b}^{f}-\mathbf{x}_{t}^{f}\right)\right\rangle, \\
& e_{a}=\left\langle\mathbf{x}_{a}^{f}-\mathbf{x}_{t}^{f}, \mathbf{C}\left(\mathbf{x}_{a}^{f}-\mathbf{x}_{t}^{f}\right)\right\rangle .
\end{aligned}
$$

To measure the observation impact on forecast error reduction, a scalar function is defined as the difference between $e_{a}$ and $e_{b}$ :

$$
J_{e}=\frac{1}{2}\left(e_{a}-e_{b}\right)
$$

The linear approximation of forecast error reduction $J_{e}$ caused by analysis increment $\mathbf{x}_{a}^{0}-\mathbf{x}_{b}^{0}$ can be expressed as

$$
\delta e=\left\langle\mathbf{x}_{a}^{0}-\mathbf{x}_{b}^{0}, \mathbf{s}\right\rangle
$$

where $\mathbf{s}$ is a properly defined vector that is expressed in terms of the forecast sensitivity to initial conditions [17, 36]. For example, $\mathbf{s}=(1 / 2)\left(\left(\partial e_{a} / \partial \mathbf{x}_{a}^{0}\right)+\left(\partial e_{b} / \partial \mathbf{x}_{b}^{0}\right)\right)$ is introduced by Langland and Baker [12] in their observation impact methodology.

In a data assimilation system, the analysis increments $\mathbf{x}_{a}^{0}-\mathbf{x}_{b}^{0}$ are represented by a best linear unbiased estimation equation

$$
\mathbf{x}_{a}^{0}-\mathbf{x}_{b}^{0}=\mathbf{K d},
$$

where $\mathbf{K}=\mathbf{A} \mathbf{H}^{T} \mathbf{R}^{-1}$ is the Kalman gain matrix, $\mathbf{A}$ represents the matrix of analysis error covariance and corresponds (at convergence) to the inverse of the Hessian matrix of the cost function $[37,38], \mathbf{H}^{T}$ is the adjoint of the observation operator, $\mathbf{R}^{-1}$ is the reverse of observation error covariance; $\mathbf{d}$ is the innovation vector $\mathbf{d}=\mathbf{y}-H\left(\mathbf{x}_{b}^{0}\right)$, $\mathbf{y}$ represents observations, and $H$ is the nonlinear observation operator. Using (A.8) and the adjoint relationship, the forecast error reduction estimation (A.7) can be expressed as

$$
\delta e=\langle\mathbf{K d}, \mathbf{s}\rangle=\left\langle\mathbf{d}, \mathbf{K}^{T} \mathbf{s}\right\rangle,
$$

where $\mathbf{K}^{T} \mathbf{s}$ is the forecast sensitivity to observations. The quantity $\delta e$, as defined in (A.9), provides the information that is required to assess observation impact using only observation space quantities. In the case $\mathbf{d}=0$ or $\mathbf{K}^{T} \mathbf{s}=0$, there is no observation impact. Typically, $e_{a}$ is smaller than $e_{b}$, so that the negative observation impact value in (A.9) is corresponding to the reduction of the forecast error due to improved initial conditions. Using (A.9), the total observation impact can be partitioned into contributions made by any individual observation or grouping of observations assimilated over the entire domain. Combining (A.4) with (A.9), the linear approximation of (A.6) can be introduced as

$$
\delta e=\left\langle\mathbf{d}, \mathbf{K}^{T}\left[\mathbf{M}_{, b}^{T} \mathbf{C}\left(\mathbf{x}_{b}^{f}-\mathbf{x}_{t}^{f}\right)+\mathbf{M}_{a}^{T} \mathbf{C}\left(\mathbf{x}_{a}^{f}-\mathbf{x}_{t}^{f}\right)\right]\right\rangle .
$$

\section{Disclaimer}

Any opinions, findings, and conclusions or recommendations expressed in this paper are those of the authors and do not necessary reflect the views of the National Science Foundation.

\section{Conflict of Interests}

The authors declare that there is no conflict of interests regarding the publication of this paper.

\section{Acknowledgment}

The National Center for Atmospheric Research is sponsored by the National Science Foundation. 


\section{References}

[1] T. S. Daniels, W. R. Moninger, and R. D. Mamrosh, "Tropospheric airborne meteorological data reporting (TAMDAR) overview," in Proceedings of the 10th Symposium on Integrated Observing and Assimilation Systems for Atmosphere, Oceans, and Land Surface (IOAS-AOLS '06), American Meteorological Society, Atlanta, Ga, USA, January 2006.

[2] A. Fischer, "The use of TAMDAR as a convective forecasting supplement in the northern plains and upper midwest," in Proceedings of the 10th Symposium on Integrated Observing and Assimilation Systems for Atmosphere, Oceans, and Land Surface (IOAS-AOLS '06), American Meteorological Society, Atlanta, Ga, USA, January 2006.

[3] N. Jacobs, Y. Liu, and C. Druse, "Evaluation of temporal and spatial distribution of TAMDAR data in short-range mesoscale forecasts," in Proceedings of the 10th Symposium on Integrated Observing and Assimilation Systems for the Atmosphere, Oceans, and Land Surface (IOAS-AOLS '06), Amer. Meteor. Soc., Atlanta, Ga, USA, January 2006.

[4] Y. Liu, N. A. Jacobs, W. Yu et al., "An OSSE study of TAMDAR data impact on mesoscale data assimilation and prediction," in Proceedings of the 11th Symposium on Integrated Observing and Assimilation Systems for the Atmosphere, Oceans, and Land Surface (IOAS-AOLS '07), American Meteorological Society, San Antonio, Tex, USA, January 2007.

[5] F. Gao, X. Zhang, N. A. Jacobs, X.-Y. Huang, and P. P. Childs, "Estimation of TAMDAR observational error and assimilation experiments," Weather and Forecasting, vol. 27, no. 4, pp. 856877, 2012.

[6] W. R. Moninger, S. G. Benjamin, B. D. Jamison, T. W. Schlatter, T. L. Smith, and E. J. Szoke, "Evaluation of regional aircraft observations using TAMDAR," Weather and Forecasting, vol. 25, no. 2, pp. 627-645, 2010.

[7] H. Wang and X.-Y. Huang, "TAMDAR observation assimilation in WRF 3D-Var and its impact on hurricane Ike (2008) forecast," Atmospheric and Oceanic Science Letters, vol. 5, no. 3, p. 206, 2012.

[8] D. M. Barker, W. Huang, Y.-R. Guo, A. J. Bourgeois, and Q. N. Xiao, "A three dimensional variational data assimilation system for MM5: implementation and initial results," Monthly Weather Review, vol. 132, no. 4, pp. 897-914, 2004.

[9] X. Y. Huang, Q. Xiao, D. M. Barker et al., "Four-dimensional variational data assimilation for WRF: formulation and preliminary results," Monthly Weather Review, vol. 137, no. 1, pp. 299314, 2009.

[10] D. Barker, X.-Y. Huang, Z. Liu et al., "The weather research and forecasting model's community variational/ensemble data assimilation system: WRFDA," Bulletin of the American Meteorological Society, vol. 93, no. 6, pp. 831-843, 2012.

[11] C. Cardinali, "Monitoring the observation impact on the shortrange forecast," Quarterly Journal of the Royal Meteorological Society, vol. 135, no. 638, pp. 239-250, 2009.

[12] R. H. Langland and N. L. Baker, "Estimation of observation impact using the NRL atmospheric variational data assimilation adjoint system," Tellus Series A, vol. 56, no. 3, pp. 189-201, 2004.

[13] N. L. Baker and R. Daley, "Observation and background adjoint sensitivity in the adaptive observation-targeting problem," Quarterly Journal of the Royal Meteorological Society, vol. 126, no. 565, pp. 1431-1454, 2000.

[14] J. Morneau, S. Pellerin, S. Laroche, and M. Tanguay, "Estimation of adjoint sensitivity gradients in observation space using the dual (PSAS) formulation of the Environment Canada operational 4DVar," in Proceedings of the 2nd THORPEX International Science Symposium, WMO/TD no. 1355, WRP/THORPEX no. 7, pp. 162-163, Landshut, Germany, December 2006.

[15] L. Xu, R. Langland, N. Baker, and T. Rosmond, "Development and testing of the adjoint of NAVDAS-AR," in Proceedings of the 7th International Workshop on Adjoint Applications in Dynamic Meteorology, Obergurgl, Austria, October 2006.

[16] R. M. Errico, "Interpretations of an adjoint-derived observational impact measure," Tellus, vol. 59, no. 2, pp. 273-276, 2007.

[17] R. Gelaro, Y. Zhu, and R. M. Errico, "Examination of variousorder adjoint-based approximations of observation impact," Meteorologische Zeitschrift, vol. 16, no. 6, pp. 685-692, 2007.

[18] Y. Zhu and R. Gelaro, "Observation sensitivity calculations using the adjoint of the Gridpoint Statistical Interpolation (GSI) analysis system," Monthly Weather Review, vol. 136, no. 1, pp. 335-351, 2008.

[19] R. Gelaro and Y. Zhu, "Examination of observation impacts derived from observing system experiments (OSEs) and adjoint models," Tellus Series A, vol. 61, no. 2, pp. 179-193, 2009.

[20] W. C. Skamarock, J. B. Klemp, J. Dudhia et al., "A description of the advanced research WRF version 3," NCAR Technical Note NCAR/TN-475+STR, 2008.

[21] X. Zhang, X.-Y. Huang, and N. Pan, "Development of the upgraded tangent linear and adjoint of the weather research and forecasting (WRF) model," Journal of Atmospheric and Oceanic Technology, vol. 30, no. 6, pp. 1180-1188, 2013.

[22] T. Auligné, X.-Y. Huang, H.-C. Lin et al., "Forecast Sensitivity to Observations (FSO) - WRF/WRFPLUS/WRFDA v3.3 User's Guide," http://www2.mmm.ucar.edu/wrf/users/wrfda/Tutorials/2012_July/docs/README_FSO_v3.3.pdf.

[23] T. Auligné, Forecast Sensitivity to Observations \& Observation Impact, Lecture at WRFDA Tutorial, National Center for Atmospheric Research, Boulder, Colo, USA, 2010, http://www2 .mmm.ucar.edu/wrf/users/wrfda/Tutorials/2010_Aug/docs/ WRFDA_sensitivity.pdf.

[24] B.-J. Jung, H. M. Kim, T. Auligné, X. Zhang, X. Zhang, and X.-Y. Huang, "Adjoint-derived observation impact using WRF in the western North Pacific," Monthly Weather Review, vol. 141, pp. 4080-4097, 2012.

[25] Y. Tremolet, "First-order and higher-order approximations of observation impact," Meteorologische Zeitschrift, vol. 16, no. 6, pp. 693-694, 2007.

[26] D. N. Daescu and R. Todling, "Adjoint estimation of the variation in model functional output due to the assimilation of data," Monthly Weather Review, vol. 137, no. 5, pp. 1705-1716, 2009.

[27] G. H. Golub and C. F. Van Loan, Matrix Computations, Johns Hopkins University Press, 3rd edition, 1996.

[28] D. F. Parrish and J. C. Derber, "The National Meteorological Center's spectral statistical-interpolation analysis system," Monthly Weather Review, vol. 120, no. 8, pp. 1747-1763, 1992.

[29] J. S. Kain, "The Kain-Fritsch convective parameterization: an update," Journal of Applied Meteorology, vol. 43, no. 1, pp. 170181, 2004.

[30] S.-Y. Hong, Y. Noh, and J. Dudhia, "A new vertical diffusion package with an explicit treatment of entrainment processes," Monthly Weather Review, vol. 134, no. 9, pp. 2318-2341, 2006.

[31] T. H. Zapotocny, W. P. Menzel, J. P. Nelson III, and J. A. Jung, "An impact study of five remotely sensed and five in situ data types in the Eta Data Assimilation System," Weather and Forecasting, vol. 17, no. 2, pp. 263-285, 2002. 
[32] S. G. Benjamin, B. D. Jamison, W. R. Moninger, S. R. Sahm, B. E. Schwartz, and T. W. Schlatter, "Relative short-range forecast impact from aircraft, profiler, radiosonde, VAD, GPSPW, METAR, and mesonet observations via the RUC hourly assimilation cycle," Monthly Weather Review, vol. 138, no. 4, pp. 1319-1343, 2010.

[33] F. Rabier, E. Klinker, P. Courtier, and A. Hollingsworth, "Sensitivity of forecast errors to initial conditions," Quarterly Journal of the Royal Meteorological Society, vol. 122, no. 529, pp. 121-150, 1996.

[34] T. N. Palmer, R. Gelaro, J. Barkmeijer, and R. Buizza, "Singular vectors, metrics, and adaptive observations," Journal of the Atmospheric Sciences, vol. 55, no. 4, pp. 633-653, 1998.

[35] X. Zou, F. Vandenberghe, M. Pondeca, and Y.-H. Kuo, "Introduction to adjoint techniques and the MM5 adjoint modeling system," NCAR Technical Note Note NCAR/TN-435+STR, 1997.

[36] D. N. Daescu and R. Todling, "Adjoint sensitivity of the model forecast to data assimilation system error covariance parameters," Quarterly Journal of the Royal Meteorological Society, vol. 136, no. 653, pp. 2000-2012, 2010.

[37] A. C. Lorenc, "Analysis methods for numerical weather prediction," Quarterly Journal of The Royal Meteorological Society, vol. 112, no. 474, pp. 1177-1194, 1986.

[38] E. Kalnay, Atmospheric Modeling, Data Assimilation and Predictability, Cambridge University Press, Cambridge, UK, 2003. 

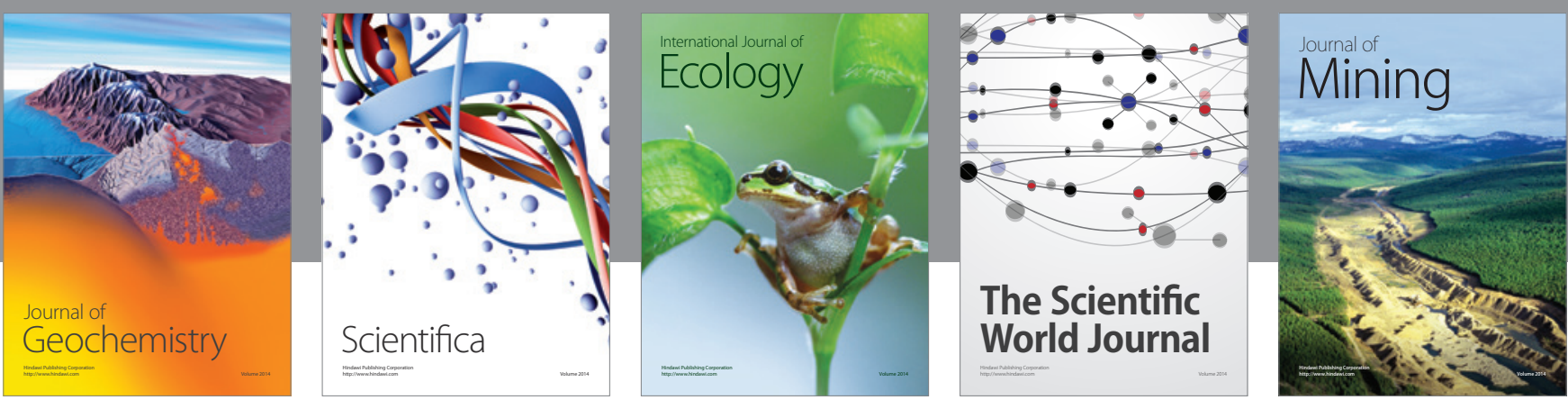

The Scientific World Journal
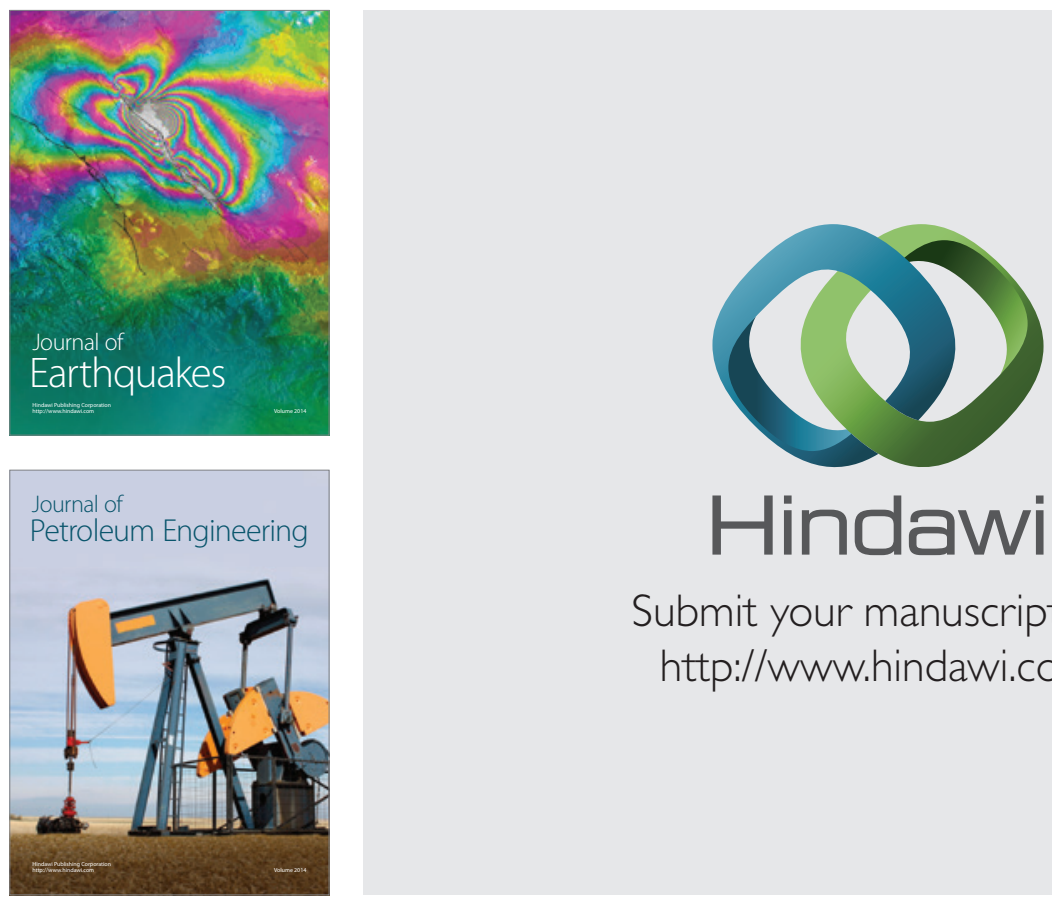

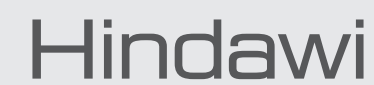

Submit your manuscripts at

http://www.hindawi.com
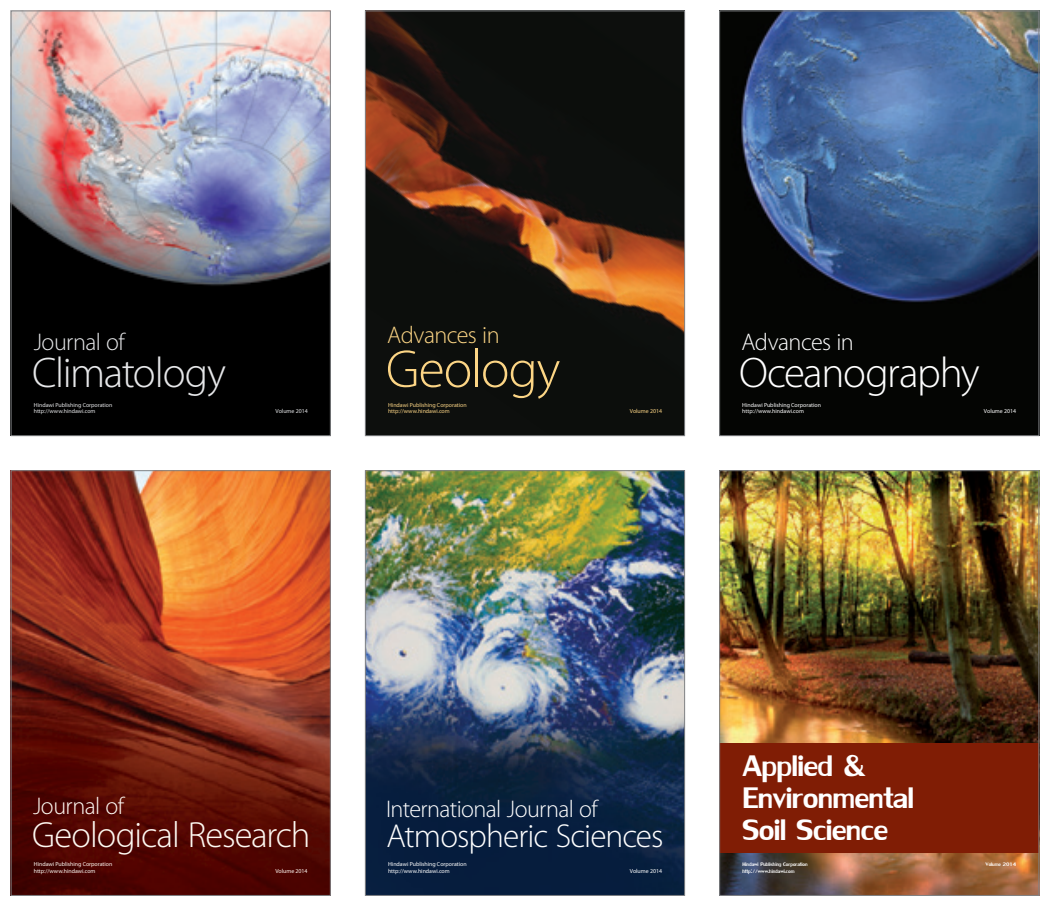
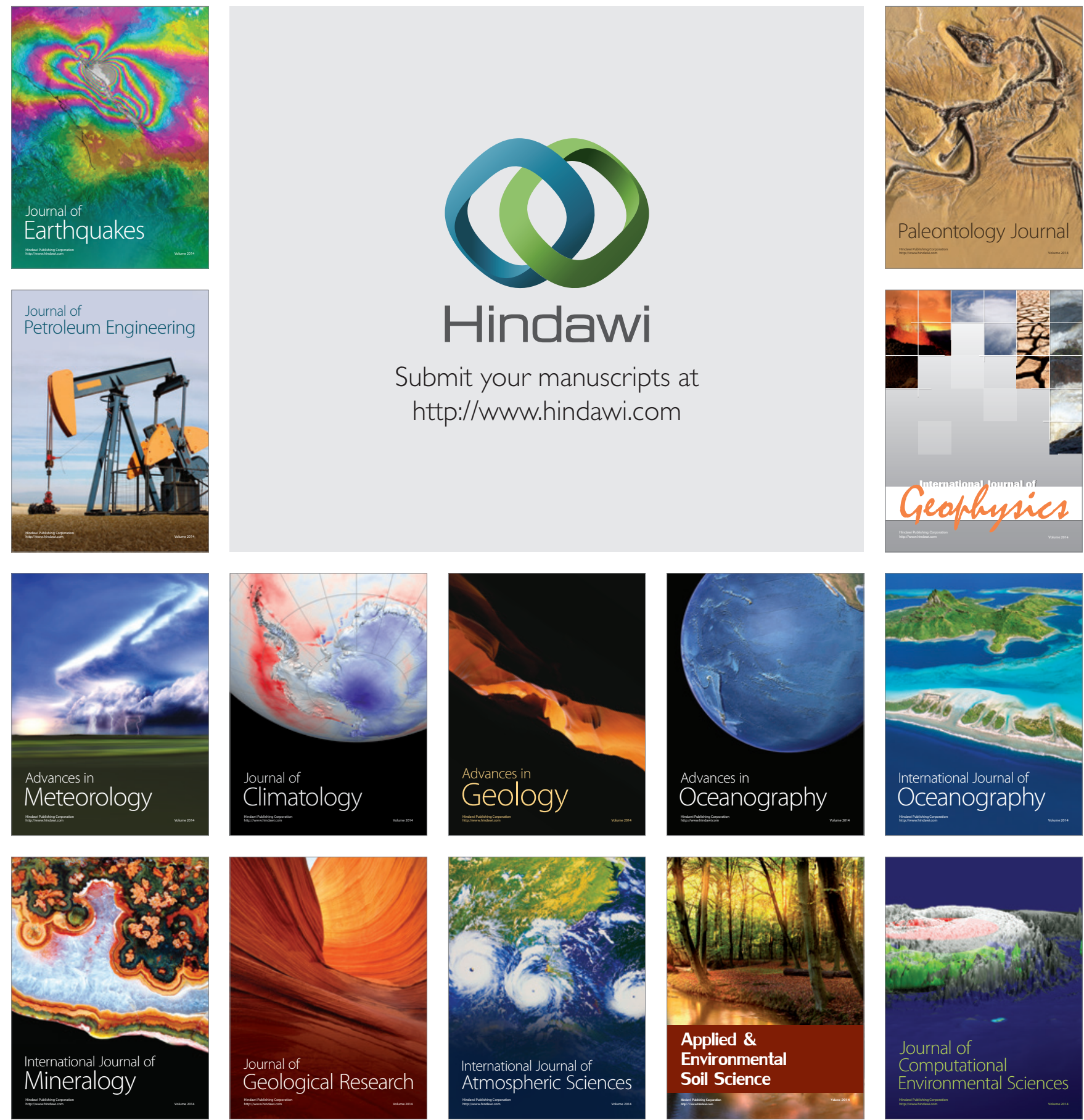